Bull. Mater, Sci., Vol. 4, No, 5, December 1982, pp. 563-568, C Printed in India.

\title{
Tetragonal to cubic phase transition in silver chlorate
}

\author{
VILAS DESHPANDE, S V SURYANARAYANA and C FRANTZ * \\ Department of Physics, University College of Science, Osmania University, \\ Hyderabad 500 007, India \\ * Laboratoire de Ge'nie Me’tallurgique E'cole de Mines, Nancy 54042, France \\ MS received 13 July 1981
}

\begin{abstract}
Silver chlorate crystallizes in the tetragonal system at room tempetature The crystal undergoes a reversible first order phase trinsition to a cubic phase at $139^{\circ} \mathrm{C}$. The tranition tem erature along with the entholpy change was determined by the DSC technique and the chrnge of enthalpy was found to be $3 \cdot 12 \mathrm{cal} / \mathrm{g}$. The high temperature form as determined by $\mathrm{x}$-ray powder diffractometric method was found to be primitive cubic with a lattice constant of $6.681 \AA$ at $145^{\circ} \mathrm{C}$.
\end{abstract}

Keywords. Silver chlorate; phase transition; x-ray diffractometry; differential scanning calorimetry.

\section{Introduction}

Silver chlorate crystallizes in the space group I $4 / \mathrm{m}$ belonging to the tetragonal system (Na'ray-Szabo' and Poc'za 1942). Recently several workers have studied the temperature dependence of the $\mathrm{NQR}$ spectrum of ${ }^{35} \mathrm{Cl}$ in $\mathrm{AgClO}_{3}$ and found that the crystal undergoes a first order phase transition above $140^{\circ} \mathrm{C}$. Shcherbakova et al (1975) have observed an abrupt change of the NQR spectrum between $142^{\circ} \mathrm{C}$ and $150^{\circ} \mathrm{C}$ accompanied by a pronounced hysterisis. Ivanov et al (1975) have found the temperature of phase transition to be $140^{\circ} \mathrm{C}$ from a dilatometric study of the crystal. Kasprzak and Pietrzak (1979) have reported that the transition occurs at $142^{\circ} \mathrm{C}$. These authors employed the NQR and $\mathbf{x}$-ray techniques and reported that the high temperature phase is cubic with a lattice constant of $9 \cdot 42 \AA$ at $162^{\circ} \mathrm{C}$.

These earlier reports do not agree on the exact temperature of phase transition. Furthermore, there is no mention of the Bravais lattice type of the high temperature phase.

The present authors have reinvestigated the problem of phase transition in $\mathrm{AgClO}_{3}$, using differential scanning calorimetric (DSC) and $\mathrm{x}$-ray diffractometric techniques in order to study the nature of the phase transition, to determine exactly the temperature of this transition and to find the Bravais lattice of the high temperature phase. 


\section{Experimental}

\subsection{Preparation and purity of the sample}

Pure $\mathrm{AgClO}_{3}$ was prepared by the procedure outlined by Nicholson and Holley (1946) which is based on a metathetic reaction between concentrated solutions of $\mathrm{AgNO}_{3}$ and $\mathrm{NaClO}_{3}$

$$
\mathrm{AgNO}_{3}+\mathrm{NaClO}_{3} \rightarrow \mathrm{AgClO}_{3}+\mathrm{NaNO}_{3} .
$$

Concentrated aqueous solutions of $\mathrm{AgNO}_{3}$ and $\mathrm{NaClO}_{3}$ were prepared with double-distilled water prepared with an all-glass distillation kit. They were taken in two separate conical flasks and then heated to $85^{\circ} \mathrm{C}$. The hot solutions were mixed together and the mixture was held at ice temperature for about $40 \mathrm{~min}$. $\mathrm{AgClO}_{3}$ precipitated as a bulky shining, white precipitate. The mother liquor was removed and the residue was washed with water cooled to $0^{\circ} \mathrm{C}$. The residue was then heated to $85^{\circ} \mathrm{C}$ once again adding some water and cooled to ice temperature. This procedure was repeated a number of times, the amount of water used in these successive stages was progressively reduced to minimise the loss of $\mathrm{AgClO}_{3}$. The impurities present in the recrystallized powder of $\mathbf{A g C l O}_{3}$ were examined by atomic absorption spectroscopy. It was found that the product was very pure and the level of impurities was negligible. Table 1 gives the details of the impurity analysis.

\subsection{Differential scanning calorimetry}

DSC traces were taken with the help of a differential scanning calorimeter (Dupont 910). Two traces were taken : one that of $\mathrm{AgClO}_{3}$ and the other that of $\mathrm{NH}_{4} \mathrm{NO}_{3}$, a calibrant material. $\mathrm{NH}_{4} \mathrm{NO}_{3}$ was chosen since it has a sharp solid-solid phase transition at $125.2^{\circ} \mathrm{C}$. The enthalpy of its endothermic phase change is accurately known to be $16.6 \mathrm{cal} / \mathrm{g}$ (Blazek 1972). The heating rate of $10^{\circ} \mathrm{C} / \mathrm{min}$ was employed throughout the experiment and a dynamic atmosphere was maintained

Table 1. Impurity analysis of $\mathrm{AgClO}$,

$\begin{aligned} & \text { Analysis of } \\ & \text { AgNOs }\end{aligned}$
$\begin{aligned} & \text { Analysis of } \\ & \mathrm{NaClO}_{3}{ }^{\circ}\end{aligned}$


around the sample pan and the empty reference pan by flowing nitrogen gas. In the present experimental arrangement the thermocouples were attached to the base of the sample and reference pans. Under these conditions the transition temperature is given by the initial departure of the trace from the baseline (Daniels 1972, p. 112).

In DSC studies the change in the enthalpy of a sample undergoing a phase transition is given by the relationship (Daniels 1972, p. 129)

$$
\triangle H=K^{\prime} A / m
$$

where $K^{\prime}$ is the calibration factor, $A$ is the area under the peak, $m$ is the sample mass and $\triangle H$ is the change in enthalpy. Here it is assumed that the same sensitivity of the instrument is used for recording the traces of the substance and the calibrant. The known enthalpy change in $\mathrm{NH}_{4} \mathrm{NO}_{s}$ was used to evaluate the calibration factor.

\subsection{X-ray powder diffractometry}

The $\mathrm{x}$-ray powder diffractograms were taken with a diffractometer (Berthold $\theta-60$ ) based on the Bragg-Brentano geometry (Frantz 1970). Cobalt $K_{a_{i}}$ radiation obtained with a quartz crystal monochromator was used. The diffractometer had arrangements for heating the specimen to any desired temperature which could be measured and controlled to an accuracy of $\pm 1^{\circ} \mathrm{C}$. The specimen could be maintained under a vacuum of the order of $10^{-6}$ torr. The specimen was in the form of a platelet of dimensions $25 \times 20 \times 2 \mathrm{~mm}$, obtained by compressing the powder to a pressure of about $1.10 \times 10^{8} \mathrm{NT} / \mathrm{m}^{2}$. Bragg angles from $8^{\circ}$ to $67^{\circ}$ could be covered in any run.

\section{Results and discussion}

\subsection{Temperature and enthalpy of phase transition}

Figure 1 shows the $\mathrm{LSC}$ traces of $\mathrm{AgClO}_{3}$ and $\mathrm{NH}_{4} \mathrm{NO}_{3}$. The existence of a sharp endothermic peak in the trace of $\mathrm{AgClO}_{3}$ confirms the observation made by Ivanov et al (1975) that the transformation is a first order solid-solid phase transition (Daniels 1972, p. 108). From the initial departure of the base lines and taking the transition temperature of $\mathrm{NH}_{4} \mathrm{NO}_{3}$ to be $125 \cdot 2^{\circ} \mathrm{C}$ the temperature of transition of $\mathrm{AgClO}_{3}$ is estimated to be $139^{\circ} \mathrm{C}$. With the known values of the weights of the sample $(30 \mathrm{mg})$ and that of the calibrant $(4.8 \mathrm{mg})$ the value of the change in enthalpy of $\mathrm{AgClO}_{3}$ comes out to be $0.596 \mathrm{k} \mathrm{cal} / \mathrm{mol}$.

\subsection{Values of the lattice parameters below and above the phase transition}

A full diffractometric trace of the tetragonal phase was recorded at $23^{\circ} \mathrm{C}$. Using the high angle reflections of this phase and employing Cohen's (1935) method in conjunction with the error function $\sin ^{2} 2 \theta$, accurate values of the lattice parameters were obtained. The standard errors in the values were calculated by the method of Jette and Foote (1935). In table 2, a comparison of the lattice parameters of $\mathrm{AgClO}_{3}$ as determined by different authors is given. The agreement is found to be fair, 


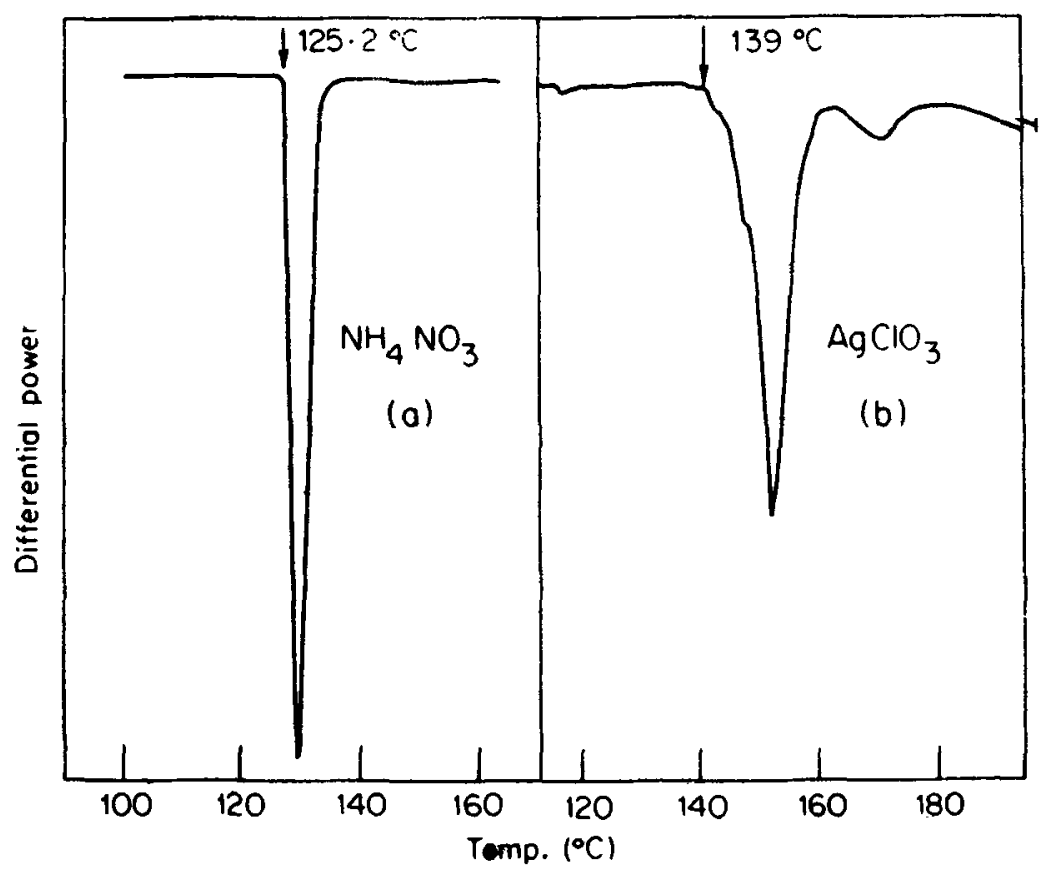

Figure 1. DSC trcees of $\mathrm{NH}_{4} \mathrm{NO}_{3}$ and $\mathrm{AgClO}_{3}$.

The sample was heated to and maintained at $140^{\circ} \mathrm{C}$ for about $12 \mathrm{hr}$ and an $x$-ray diffractogram was recorded thereafter. The trace clearly indicated that the transition was complete and no peak of the tetragonal phase was observed. Another full diffractometric trace collected at $145^{\circ} \mathrm{C}$ was used for a detailed analysis of the new phase. Table 3 lists the $\sin ^{2} \theta$ values and the relative intensities of the first 23 reflections, from this diffractogram. It can be immediately seen that the $\sin ^{2} \theta$ values of the six initial reflections are in the ratio of $2: 3: 4: 5: 6: 8$. The absence of 1 and 7 from this sequence of the numbers suggests that the first reflection of the lowest Bragg angle has not been registered, because of the limitations of $\theta$ scan at the lower angle side, and that the crystal has either a primitive $(P)$ or a body centered cubic $(I)$ lattice (Henry et al 1953). In order to fix the Bravais lattice unambiguously the $N\left(=h^{2}+k^{2}+l^{2}\right)$ values were calculated for all the reflections on the basis of an $I$ or a $P$ lattice. These are given in columns 4 and 5 of table 3 respectively. A study of these columns shows that

(a) all the forbidden values of $N$, viz., 7, 15, 23 and 28 are absent from the $P$-lattice,

(b) the two forbidden values of $N$, viz., 28 and 60 are both present in column 4 for the I-lattice,

(c) although not forbidden as such, the linis with $N$ equal to 14, 30, 46 and 56 are all absent from the column no. 4. These numbers are twice the forbidden $N$ values in the case of the $P$ lattice.

These observations clearly establish that the high temperature phase of $\mathrm{AgClO}_{3}$ has a primitive cubic structure, Using the high angle reflections of this diffracto- 
Table 2. Lattice parameters of $\mathrm{AgClO}_{3}$ at room temperature.

\begin{tabular}{lrr}
\hline Source & $a(\AA)$ & $c(\AA)$ \\
\hline Swanson et al (1955) & 8.498 & 7.938 \\
Na'ray-Szabo' and Poc'za & & \\
$\quad$ (1942) & 8.503 & 7.910 \\
Present study & 8.492 & 7.919 \\
& \pm 0.002 & \pm 0.004 \\
\hline
\end{tabular}

Table 3. Analysis of the diffractometric trace of $\mathrm{AgClO}_{3}$ at $145^{\circ} \mathrm{C}$.

\begin{tabular}{|c|c|c|c|}
\hline \multirow[b]{2}{*}{$\sin ^{2} \theta$} & \multirow{2}{*}{$\begin{array}{l}\text { Relative } \\
\text { intensity }\end{array}$} & \multicolumn{2}{|c|}{$\mathbf{N}$} \\
\hline & & $\mathrm{BCC}$ & Primitive \\
\hline 0.0365 & 28 & 4 & 2 \\
\hline 0.0544 & 46 & 6 & 3 \\
\hline 0.0703 & 47 & 8 & 4 \\
\hline 0.0905 & 100 & 10 & 5 \\
\hline $0 \cdot 1083$ & 33 & 12 & 6 \\
\hline $0 \cdot 1444$ & 65 & 16 & 8 \\
\hline $0 \cdot 1625$ & 100 & 18 & 9 \\
\hline $0 \cdot 1809$ & 43 & 20 & 10 \\
\hline $0 \cdot 1991$ & 9 & 22 & 11 \\
\hline $0 \cdot 2164$ & 6 & 24 & 12 \\
\hline $0 \cdot 2347$ & 45 & 26 & 13 \\
\hline 0.2528 & 100 & 28 & 14 \\
\hline $0 \cdot 3057$ & 95 & $\overline{34}$ & 17 \\
\hline $0 \cdot 3247$ & 49 & 36 & 18 \\
\hline $0 \cdot 3427$ & 13 & 38 & 19 \\
\hline $0 \cdot 3602$ & 7 & 40 & 20 \\
\hline $0 \cdot 3787$ & 10 & 42 & 21 \\
\hline $0 \cdot 3958$ & 18 & 44 & 22 \\
\hline 0.4505 & 6 & 50 & 25 \\
\hline $0 \cdot 4683$ & 30 & 52 & 26 \\
\hline 0.4862 & $7 \cdot 5$ & 54 & 27 \\
\hline 0.5220 & 17 & 58 & 29 \\
\hline $0 \cdot 5401$ & 12 & 60 & 30 \\
\hline
\end{tabular}

gram and the procedure indicated earlier for the determination of the values of the lattice parameters, the lattice constant of the primitive cubic crystal was found to be $6.681 \pm 0.001 \AA$ at $145^{\circ} \mathrm{C}$. This value is in complete disagreement with the one given by Kasprzak and Pietrzak (1979), viz., 9.42 $\AA$. This disagreement could be explained if the lattice constant is calculated on the assumption that the high temperature phase is body centred. The value of ' $a$ ' calculated using the first few low angle reflections comes out as $9 \cdot 44 \AA$, which agrees well with that reported by Kasprzak and Pietrzak (1979). It appears therefore that these workers had limited their analysis to the first few reflections, 
The volume of the tetragonal unit cell at $23^{\circ} \mathrm{C}$ is about $579 \AA^{3}$. As there are 8 molecules in the unit cell (Nar'ay-Szabo' and Poc'za 1942) the volume occupied by a single $\mathrm{AgClO}_{3}$ molecule is about $71 \AA^{3}$. It is reasonable to expect that in the cubic phase the volume occupied by a single molecule would be of the same order although slightly larger due to the effects of the rise of temperature and also due to the discontinuous change of volume occurring during the first order phase transition. The volume of the primitive cubic cell at $145^{\circ} \mathrm{C}$ is about $298 \AA^{3}$. If the number of molecules in this cell is assumed to be four, the volume occupied by a single molecule would be equal to $74 \AA^{3}$. Thus it appears reasonable to conclude that in the high temperature cubic phase of $\mathrm{AgClO}_{3}$ there would be 4 molecules/unit cell.

\section{Conclusions}

Silver chlorate is found to undergo a first order phase transition at $139^{\circ} \mathrm{C}$ to a primitive cubic phase and the enthalpy change involved is $0.596 \mathrm{k} \mathrm{cal} / \mathrm{mol}$. The lattice parameter in the cubic phase is $6.681 \pm 0.001 \AA$ at $145^{\circ} \mathrm{C}$.

\section{Acknowledgements}

The x-ray diffractograms were taken during the visit of one of the authors (svs) in summer 1980 to Ecole de Mines, Nancy, on a visiting fellowship. He thanks the authorities of Osmania University for deputing him to Ecole de Mines. The authors thank Prof. V T Deshpande of Osmania University and Prof. G. Champier of Ecole de Mines for many useful discussions. They thank Dr K M Kamath and Dr P G Agashe of the Bharat Heavy Electricals Limited, Hyderabad, for the use of DSC facilities.

\section{References}

Blazek A 1972 Thermal analysis (London : Van Nostrand Reinhold Company)

Cohen M U 1935 Rev. Sci. Instrum. 668

Daniels T 1973 Thermal analysis (London: Kogan Page)

Frantz C 1970 Etude radiocristallographique quantitative des transformations ordre-desordre dans les alliages cadmium-m.gnesium (Dacteur-es-Sciences Physiques), University of Nancy, France.

Henry N F, Lipson $H$ and Waaster W A 1953 The interpretation of $x$-ray diffraction photographs (London : Macmilian) p. 240

Ivanov I P, Boguslavskii A A, Lotfullin R S H and Zenkov A P 1975 Izv. Akad. Nauk SSSR, Ser. Fiz. 392513

Jette $\mathrm{E} R$ and Foote F $1935 \mathrm{~J}$. Chem. Phys. 3605

Kasprzak J and Petrzak J 1979 Phys. Status. Solidi. A55 K115

Na'ray-Szaba' I and Pac'za J 1942 Z. Kristallogr. 10428

Nicholson D G and Holley C E 1946 Inorganic synthesis Vol. II (New Yark : MeGraw-Hill) p. 4

Shcherbakova S K, Boguslavskii A A, Burbelo V M and Lotfullin R S H 1975 Izv. Akad. Nauk SSSR, Ser. Fiz. 392505

Swanson H E, McMurdie H F, Morris M C and Evans E H 1957 NBS Circular 539744 